\title{
«La voz de la conciencia». La conexión noológica de moralidad y religiosidad en Zubiri

\author{
«The voice of conciousness».
}

The noological nexus between Morality and Religiosity in Zubiri's philosophy

Jesús CONILL-SANCHO

Universidad de Valencia

RESUMEN. Estudio de la noción «voz de la conciencia» en la obra de Xavier Zubiri, tras una contextualización histórica del tema, mostrando su importancia en las obras más tardías, así como su conexión con las fuentes más relevantes en el pensamiento contemporáneo, en especial, la Fenomenología y la Analítica existencial de Heidegger. Se destaca la aportación zubiriana del análisis noológico de la voz de la conciencia, que distingue la experiencia moral y la religiosa, pero que descubre, a su vez, una peculiar conexión entre lo moral y lo religioso.

Palabras clave: Conciencia, Noología, Moralidad, Religiosidad, Zubiri, Religación, Deidad, Poder.
Abstract. Study of the notion «voice of conciousness» in the works of Xavier Zubiri, after a historic view, showing its relevance in the last works and its connection with the most important sources in the contemporary thought, specially Phenomenology and Heidegger's Existential Analitic. It stands out the noological analysis of the voice of conciousness, which distinguishes moral and religious experience, but also reveals the deep bond between morality and religiosity.

Key words: Conciousness, Noologic, Morality, Religiosity, Zubiri, Religation, Deity, Power.

No se ha prestado hasta ahora una especial atención al significado de la expresión «la voz de la conciencia» en la filosofía de Zubiri y, sin embargo, a mi juicio, constituye una pieza clave de su analítica noológica de la facticidad ${ }^{1}$. Para mostrarlo, hemos de comenzar localizando el uso de tal expresión en las obras de Zubiri, con el propósito de descubrir su peculiar significación, sobre todo en las obras de madurez, tras una contextualización histórica del tema.

1 Este texto fue preparado para la sesión del Seminario de Investigación de la Fundación Xavier Zubiri del día 3 de abril de 2009 sobre «La voz de la conciencia». 


\section{Localización del término «la voz de la conciencia»}

El término «la voz de la conciencia» aparece sólo en la denominada «trilogía teologal» de la época de madurez de Zubiri ${ }^{2}$, en el contexto de su tratamiento de la religación y, sin embargo, no aparece en las versiones tempranas que sobre este asunto se encuentran en Naturaleza, Historia, Dios $[\mathrm{NHD}]^{3}$.

La «voz de la conciencia» es una noción que aparece en el análisis del hecho de la religación, concretamente al exponer el «problematismo de la fundamentalidad» en la versión de El hombre y Dios [HD], donde se resalta que «estamos fundados en un enigma, el enigma del poder de lo real».

Curiosamente, tanto la noción de la «voz de la conciencia» como la del «poder de lo real» no aparecen en la versión temprana de la religación de $N H D$, justamente en los textos que más se suelen relacionar con su etapa de más vinculación a Heidegger. Sin embargo, aparecen en los textos de su etapa de madurez, hasta los del tramo final de su vida, como es la primera parte de $H D$. Por tanto, esta localización podría ser significativa. Lo más probable es que el significado específico que le confiere Zubiri ya no dependa del pensamiento heideggeriano, sino que haya adquirido un sentido peculiar dentro de su propia filosofía.

En cambio, en $N H D$ aparece un término que tiene cierto parecido: la «vOz de las cosas» ${ }^{4}$. Pero en este caso es «una voz que dicta» el «logos» y forma parte del sentir «íntimo», pero que, a su vez es la «voz de las cosas», de las que nos dicta su ser y nos lo hace decir. Pues el hombre dice lo que dice por «la fuerza de las cosas». Zubiri aclara que es mi sentir íntimo el que siente esta voz de las cosas y que este sentir es un «escuchar» para «seguir» lo que en ella se dice y así entregarnos a las cosas. Por tanto, quien atiende a la voz de las cosas está "despierto» a ellas, vigilante. Cuando se descubre una cosa, es como si se despertase a ella. Y de ahí que el primer logos del despertar sea un «ex-clamar». Así pues, el hablar del hombre despierto será «el portavoz de las cosas».

Complementariamente a estas consideraciones se encuentra la perspectiva socrática, en la que la sabiduría se entiende como ética. Sócrates viene a ser el creador de un nuevo tipo de vida intelectual y de sabiduría. Su pensamiento es «sonoro», es el diálogo en forma de pensamiento. En él se nos dice cómo se va a vivir: meditando con la mente (noûs), conociéndose a sí mismo, escrutando con el noûs de cada cual la voz que dicta lo que «es» la virtud. He ahí el êthos como modo o forma de vida y que consiste en vivir meditando.

2 El hombre y Dios [HD] (1984), El problema filosófico de la historia de las religiones [PFHR](1993) y El problema teologal del hombre: Cristianismo [PTHC] (1997) (vid. la correspondiente «Presentación» de Antonio González). (1963).

3 «En torno al problema de Dios» (1935 y 1936) y «Introducción al problema de Dios»

4 «¿Qué es saber?» (1935); «Sócrates y la sabiduría griega» (1940). 
En este contexto socrático, «la verdad se encuentra soportada por un êthos», «acontece en un cierto modo de la existencia humana». Para Sócrates, «se trata de una voz divina, que emerge del fondo del que habla (daimónion)» ${ }^{5}$.

Sin embargo, en los contextos que más tarde van a ser los lugares en que aparezca el término «la voz de la conciencia», que son los relativos a la religación, en $N H D$ no se encuentra dicho término. Tan sólo encontramos en la «Introducción al problema de Dios» una referencia a la «conciencia moral», que - según veremos - se ha relacionado tradicionalmente con «la voz de la conciencia», pero en este contexto zubiriano lo que se resalta es precisamente la diferencia que existe entre lo que este término expresa y la religación. La «apertura a la deidad» (como «carácter último de lo real», como ultimidad religante y enigmática) no es «el resultado de la conciencia moral», sino al contrario, la conciencia moral es lo que es «sólo en y por la religación», por tanto, la conciencia moral sería «algo suscitado por la religación» ${ }^{6}$.

No obstante, todavía podría preguntarse si existe algún rastro, alguna huella o indicio, de la voz de la conciencia en los textos relativos a la religación en $N H D$, porque puede resultar muy extraño no encontrar absolutamente nada que se refiera a ella en una etapa tan normalmente conectada con Heidegger y teniendo en cuenta que, como ha señalado Diego Gracia, «el término, como es obvio, procede de Heidegger» ${ }^{7}$.

\section{Contextualización histórica (antigua y moderna)}

La expresión como tal no aparece en la Biblia, sino que allí encontramos otros términos que podrían ejercer una función semejante, como «corazón»e «interior». En la Filosofía Griega, concretamente se atribuye a Sócrates la referencia a una «voz interior» de carácter «demoníaco» (daimónion) y «divino» (theîon), a la que ya hemos aludido, porque Zubiri remite a ella en algunos de sus trabajos.

Pero el lugar canónico de «la voz de la conciencia» en la historia del pensamiento se encuentra en los Estoicos. En ella resuena la voz racional (lógos) de la naturaleza (physis). Siguiendo la doctrina estoica antigua se la denomina «pneûma», Cicerón y Séneca la consideran un espíritu en nuestro interior, una fuerza, un poder, una rectitud, una «scintilla», la expresión de la «nata $l e x{ }^{8}$. No es raro, pues, que bajo la influencia estoica, «la voz de la concien-

5 Vid. también Cursos universitarios. Volumen I, Alianza y Fundación X. Zubiri, Madrid, 2007 (que recogen lecciones de cursos de 1931 y 1932), p. 113.

${ }^{6}$ Un texto añadido en la 5 . $^{\text {a }}$ edición de 1963 , del que dice que proviene de una lección dada hacía más de quince años. Cfr. NHD, 411-412.

7 Cfr. Diego Gracia, Voluntad de verdad, Triacastela, Madrid, 2007, p. 217.

8 Vid. H. Reiner, «Gewissen», Historisches Wörterbuch der Philosophie, Bd. 3, Schwabe \& Co., Basel/Stuttgart, 1974, pp. 574-592. 
cia» se convirtiera en la potencial manifestación y expresión de «la voz de Dios». El mismo San Pablo recurrió a las mediaciones estoicas para comprender la experiencia del bien y del mal, que todos los hombres comparten, porque todos llevan escrita en su corazón la misma ley moral; el hombre con su razón, en su interioridad, sabe distinguir el bien y el mal ${ }^{9}$. Emerge aquí, pues, el problema de la conciencia moral.

En la tradición se han utilizado diversos términos que son convergentes («acies cordis», «mens», «animi acies», «fondo espiritual»), pero fueron los términos «scintilla conscientiae» y «sindéresis» los que tuvieron más éxito para expresar de algún modo el conocimiento de la ley natural en la conciencia moral. Aunque fuera en forma de indicación, susurro, atisbo o "chispa», la voz divina resonaba en el hombre a través de la voz de la conciencia, distinguiendo entre el bien y el mal.

La concepción moral de la conciencia mediante el término "Gewissen» adquiere un lugar privilegiado en la filosofía kantiana. La conciencia moral (Gewissen) «es una conciencia (Bewusstsein) que es para sí misma deber $($ Pflicht $) \gg{ }^{10}$. Y todo hombre, como ser moral, tiene originariamente en sí conciencia moral ${ }^{11}$.

En la conciencia moral lo que ocurre es que «la razón se juzga a sí misma» y se atiende a «la voz del juez interior», porque la conciencia moral es la conciencia de un tribunal interno al hombre, cuya voz no puede dejar de oírse. Ha de pensarse la conciencia moral, pues, como el principio subjetivo de la responsabilidad de los propios actos, que nos orienta en la vida desde el interior de nosotros mismos.

En el propio Kant encontramos expresiones más ricas de lo que se han solido reconocer y que rebasan la interpretación exclusivamente subjetivizadora que se ha atribuido a la filosofía moderna en general. De hecho, Kant considera la conciencia moral (Gewissen), no sólo como «la ley en nosotros», sino como «Vermögen» $\mathrm{y}$ «Anlage» ${ }^{12}$. Es más, primero, la considera «un hecho (Tatsache) inevitable, no una obligación y un deber»; pues «no se relaciona con un objeto, sino únicamente con el sujeto (afectando al sentimiento moral con su acto)» ${ }^{13}$. En segundo lugar, Kant considera que la conciencia moral es «la conciencia de un tribunal interno al hombre», un «poder» (Gewalt) que mantiene en vela al hombre y que «está incorporado a su ser» (seinem Wesen einverleibt), por eso «le sigue como su sombra» y «no puede evitar» oír su «voz». En tercer lugar, por su conciencia moral el hombre "se ve forzado» (en su quehacer consigo mismo) «como si fuera por orden de otra persona»,

${ }^{9}$ Cfr. Rom 1 y 2, 13-14 y 26; 7, 22-23. p. 181 .

10 I. Kant, La religión dentro de los límites de la mera razón, Alianza, Madrid, 1969,

11 I. Kant, La Metafísica de las Costumbres, Tecnos, Madrid, 1989, p. 255.

12 Vid. respectivamente: Pädagogik, IX, 495; KpV, V, 98; Met. Sitt., VI, 438.

13 I. Kant, La Metafisica de las Costumbres, pp. 255-256. 
teniendo que imaginar como juez «a otro», lo cual ha conducido a pensar «la conciencia moral como el principio subjetivo de la responsabilidad de los propios actos ante Dios» ${ }^{14}$. Y, en cuarto lugar, este último concepto - el de Dios- está siempre contenido en la autoconciencia moral, «aunque sólo de un modo oscuro», por eso Kant considera que por medio de esta idea lo que el hombre recibe es una «orientación» (Leitung): «representarse la escrupulosidad (Gewissenhaftigkeit) (que también se llama "religio") como responsabilidad ante un ser santo (ante la razón moralmente legisladora), distinto de nosotros mismos, pero íntimamente presente en nosotros, y someter la propia voluntad a las reglas de la justicia. El concepto de religión en general es aquí para el hombre únicamente "un principio para considerar todos sus deberes como mandatos divinos"» 15 .

Esta idea de la religión a la que alude Kant aquí se parece bastante a la que se encontrará también en algunos textos de Ortega y Gasset, tanto en los que se entiende la religiosidad a partir del adjetivo «religiosus», que significa escrupuloso, cuidadoso (y no a partir del substantivo «religio», entendido como ligazón o vínculo), como en otros textos en los que se relaciona con el ideal moral ${ }^{16}$.

No obstante, y a pesar de la riqueza que cabe encontrar en la filosofía de Kant a Hegel, hemos asistido a una crítica de la concepción moderna de la conciencia por diversas vías. En primer lugar, se extendió la idea de que se ha producido una ruptura con respecto al ser y la objetividad, por tanto, que se ha caído en un insuperable subjetivismo, que ha significado un déficit ontológico, un nueva forma de «olvido del ser» (Heidegger), o bien ha conducido a la «anarquía moral» (Scheler). Por otra parte, se han desarrollado una serie de duras críticas de la conciencia moral a través de la Genealogía de Nietzsche, el Psicoanálisis de Freud y el Materialismo Histórico de Marx, que han mostrado que por detrás de la conciencia hay «una larga historia, una prolongada metamorfosis», ya sea en virtud de instintos (Nietzsche), fuerzas energéticas del organismo (Freud) o procesos sociales determinantes (Marx). Y, por último, habría que señalar que, incluso en quienes se han ocupado de nuevo - y de un modo muy fecundo- de la conciencia moral en algunas éticas procedimentales, se ha producido una psico-sociologización creciente ${ }^{17}$. Resulta, al menos curioso, que en Apel y Habermas no se encuentre usado el término «Gewissen», sino «Moralbewusstsein» (o «moralisches Bewusstsein»), o

14 Ibid., pp. 303-305.

15 Ibid., p. 305.

16 José Ortega y Gasset, Obras completas, VI, 64; I, 133-136. Vid. Jesús Conill, «De la religión de la vida a la religión personal en Ortega y Zubiri», The Xavier Zubiri Review, vol. 8 (2006), pp. 93-101.

17 Karl-Otto Apel, Transformación de la filosofia (Taurus, Madrid, 1985) y Jürgen Habermas, Conciencia moral y acción comunicativa (Península, Barcelona, 1985); Lawrence Kohlberg, Psicología del desarrollo moral, DDB, Bilbao, 1992. 
bien que en Rawls prácticamente haya desaparecido la noción de conciencia moral.

¿Implica este proceso de insistente crítica de la conciencia moral una disolución del fenómeno básico del que se estaba tratando o es posible descubrir un nuevo nivel desde el que resituar la conciencia moral mediante la reflexión filosófica? ¿Aceptó Zubiri la problematicidad de la conciencia moral, a que habían conducido las críticas contemporáneas? ¿Se propuso recuperar su estatuto, pero en un nuevo marco filosófico? ¿Dónde y cómo cabría situar la conciencia moral en la nueva analítica noológica de la intelección sentiente?

Según Diego Gracia ${ }^{18}$, Zubiri se sumó a la búsqueda de una alternativa a la crítica de la conciencia moral, que el propio Zubiri habría asumido, y de ahí su reticencia hacia la ética, por sus connotaciones moralistas. La alternativa zubiriana iría en la dirección de una radicalización metafísica - luego complementada en la versión noológica - frente al moralismo. Y, al parecer, una orientación semejante es la que le llevó también a preferir a los Padres griegos frente a los latinos.

\section{Contextualización de la alternativa zubiriana}

Los métodos filosóficos a los que pudo recurrir Zubiri para situar una alternativa a las críticas de la conciencia moral, en un contexto de búsqueda, a su vez, de superación del Idealismo y del Positivismo, fueron la Fenomenología y la Analítica existencial.

La Fenomenología como tal de Husserl y Scheler conducía de nuevo a la subjetividad de la conciencia y a su carácter moral, que sólo podría salvar el inapelable subjetivismo y la consiguiente anarquía moral mediante una intuición objetiva (estimativa) de los valores, al estilo de Scheler ${ }^{19}$.

La nueva Fenomenología de Heidegger, en la versión de su Analítica existencial, por su parte, nos remite al contexto de la compleja relación entre Zubiri y Heidegger ${ }^{20}$. Podemos comenzar recordando la ubicación contextual de nuestro tema — «la voz de la conciencia»- con las palabras de Diego Gracia: «el término, como es obvio, procede de Heidegger». Recurramos, pues, a la exposición de Heidegger en Ser y tiempo, que es donde recibe un tratamiento sistemático la noción de «voz de la conciencia» y que nos permi-

18 Así lo expresó en la sesión del Seminario de Investigación Xavier Zubiri del 3 de abril de 2009. Vid. una aclaración del contexto de este tema en Diego Gracia, Como arqueros al blanco (Triacastela, Madrid, 2004, cap. 7).

19 Vid. Edmund Husserl, Renovación del hombre y de la cultura (Anthropos, Barcelona, 2002), pp. 40, 48 y 50; Max Scheler, Ética, Caparrós, Madrid, 2001, pp. 432-444.

20 Vid. Juan Antonio Nicolás y Ricardo Espinosa (eds.), Zubiri ante Heidegger (Herder, Barcelona, 2008). 
tirá comprender el posible aprovechamiento del análisis heideggeriano y el distanciamiento con respecto al mismo por parte de Zubiri.

El análisis existencial ${ }^{21}$ (que apunta hacia una ontología fundamental) considera la «voz de la conciencia» como «un fenómeno originario del Dasein». El presunto análisis ontológico de la conciencia ofrecido por Heidegger quiere situarse en un espacio propio y de ahí que lo deslinde explícitamente de otros tres posibles tratamientos: 1) pretende ser previo a la descripción psicológica de las vivencias de la conciencia moral; 2) es ajeno a una «explicación» biológica, que equivaldría a una «disolución del fenómeno»; y 3) guarda distancia de una interpretación teológica de la conciencia o de la utilización de este fenómeno como una «inmediata» conciencia de Dios.

Por tanto, Heidegger cree que su análisis de la conciencia nos descubre un fenómeno más allá de las consideraciones de la Psicología, la Biología y la Teología, porque nos desvela la conciencia, en cuanto fenómeno del Dasein, como factum tan sólo en y con la existencia fáctica. Y un análisis más a fondo de la conciencia la revela como una llamada (Ruf). Esta llamada tiene el carácter de una apelación (Anruf) al Dasein a hacerse cargo de su más propio poder-ser-sí-mismo, y esto en el modo de una intimación (Aufruf) a despertar a su más propio ser-culpable (Schuldigsein).

Según el análisis heideggeriano, la llamada de la conciencia no le dice nada en concreto al interpelado, sino que éste solamente es llamado hacia sí mismo, hacia su más propio poder-ser. Heidegger describe el fenómeno así: «La llamada procede de mí y, sin embargo, de más allá de mí». Ahora bien, «esta constatación fenoménica» es la que ha servido de «punto de partida para la interpretación de la voz como un poder ajeno que se alzaría dentro del Dasein» ${ }^{22}$. Y «suele adjudicársele el poder constatado a un poseedor, o se lo considera a él mismo como manifestación personal (de Dios)»; «o por el contrario, se intenta rechazar esta interpretación del vocante como manifestación de un poder ajeno, eliminando al mismo tiempo la conciencia en general mediante una interpretación "biológica" de ella».

Pero «ambas interpretaciones desatienden la constatación fenoménica», debido a una «precipitación metodológica». Y, por eso, Heidegger exige mantener lo fenoménicamente constatado: «que la llamada, procediendo de mí y de más allá de mí, se dirige a mí»; y, a continuación, defiende «el bosquejo ontológico del fenómeno tal como allí se encuentra», es decir, «como un fenómeno del Dasein».

21 Cfr. Martin Heidegger, Ser y tiempo, p. 54 (traducción de Rivera; «existenciario», según la de Gaos). Heidegger aclara en nota que las consideraciones que expone aquí fueron dadas a conocer con ocasión de una conferencia sobre el concepto de tiempo en Marburgo (julio de 1924). Seguramente se refiere a la conferencia «Der Begriff der Zeit», en la Sociedad Teológica de Marburgo, celebrada el 25 de julio de 1924.

22 M. Heidegger, Ser y tiempo, ed. Rivera, p. 295. 
Como la llamada acontece en la facticidad del Dasein, en su condición de arrojado en la existencia, el que llama es el Dasein en su desazón, en su originario y arrojado estar-en-el-mundo, experimentado como un estar fuera de casa (als Un-zuhause), como el nudo "factum que...» en la nada del mundo, que se angustia por su poder-ser y de ahí que la conciencia se revele como llamada del cuidado. Pues «el Dasein, en el fondo de su ser, es cuidado».

Me parece que, hasta aquí, el análisis heideggeriano pudo ser aprovechado por Zubiri - aunque fuera a su manera - en lo que se refiere 1) a los fundamentos ontológico-existenciales de la conciencia, 2) a su carácter vocativo y 3 ) a la consideración de la conciencia como llamada del cuidado. Pero el nuevo paso que da Heidegger en su análisis de la comprensión de la llamada, intentando mostrar que lo que la llamada da a entender a través de la conciencia es la «culpa», no creo que fuera seguido por Zubiri en ningún caso. Ni tampoco creo que Zubiri haya podido compartir que lo que la conciencia proclama es la «culpabilidad», porque no creo que pudiera aceptar la siguiente afirmación de Heidegger: «Todas las experiencias e interpretaciones de la conciencia concuerdan unánimemente en que de alguna manera la "voz" de la conciencia habla de "culpa" ${ }^{23}$. Pues ni siquiera hay constancia de que la culpa o la culpabilidad ocupe algún lugar relevante en la obra zubiriana.

No obstante, la culpa o culpabilidad ha ocupado un lugar destacado en la cultura, también en la nuestra, no sólo en algunas tradiciones religiosas (sobre todo, en la versión protestante del cristianismo) ${ }^{24}$, sino también como culpabilidad moral vinculada a la subjetividad (a la interioridad de la conciencia y al foro interno) y, por tanto, como imputación. Sin embargo, el análisis heideggeriano habría descubierto una dimensión ontológica de la culpa, más allá de la experiencia moral, por la que el hombre sería «siempre culpable ya por el mero hecho de existir»».

Ahora bien, todavía habría otra posible interpretación de la «llamada» en que consiste la conciencia en términos de responsabilidad moral, aunque no en el sentido de la imputación, es decir, no para responder de los actos de un sujeto libre, sino en el sentido de la responsabilidad como «asignación» ${ }^{25}$. Este otro sentido de la responsabilidad como asignación significa responder a una llamada que precede y excede el libre compromiso del sujeto. Así como la imputación moral presupone la autonomía del sujeto, es decir, la libertad

23 Habrá más diferencias entre Heidegger y Zubiri, además de la que se refiere a la comprensión de la llamada proclamando la culpabilidad. Por ejemplo, la comprensión de la moralidad como ser-culpable [que se convertirá en un estudio de la realidad moral]; la llamada al cuidado [que se transformará en la exigencia de hacerse persona]; las raíces ontológicas [que se transformarán en la cuestión metafísica y noológica].

24 Vid. las reflexiones de José Luis L. Aranguren, «Catolicismo y protestantismo como formas de existencia», en Obras completas, 1, Trotta, Madrid, 1994, p. 339, donde insiste en el «entroque luterano» desde el que está escrito Ser y tiempo. También Manuel Fraijó, A vueltas con la religión, Verbo Divino, Estella, 1998.

25 Vid. Gabriel Amengual, Antropología filosófica, BAC, Madrid, 2007, pp. 425-428. 
moral (al modo kantiano), la asignación arraiga en una relación previa por la que uno se siente abierto y afectado por una interpelación y, entonces, la responsabilidad aparece como una llamada que se apodera de uno y lo pone en movimiento. Pues «asignar» significa algo así como señalar lo que corresponde.

Según Amengual ${ }^{26}$, han sido Levinas y Jonas quienes han conceptualizado esta segunda perspectiva, en la que la responsabilidad moral no comienza en mi compromiso y decisión, no es fruto de mi propia elección, sino en la concernencia por la presencia de otro. Hay aquí una nueva forma de «heteronomía» en el fundamento de la responsabilidad moral. Lo que rige y obliga es la responsabilidad por el otro vulnerable. El «arquetipo» de la responsabilidad moral es la llamada del otro vulnerable, que requiere protección, y no soy libre de eludir tal responsabilidad por el otro frágil y desvalido, sino que estoy impelido a cuidar al otro vulnerable, más allá de las relaciones de reciprocidad, porque en esta nueva concepción de la responsabilidad como llamada y asignación se está rebasando el círculo de la reciprocidad, en favor de otra forma prioritaria de relación moral.

A mi juicio, serían éstos los contornos más importantes del contexto en que se habría podido mover la reflexión zubiriana, cuyos trazos fundamentales expondremos a continuación, atendiendo a su «trilogía teologal».

\section{El fenómeno de la voz de la conciencia en el análisis zubiriano de la realidad humana}

En la Primera parte de $H D$ (1984), dedicada al análisis de la realidad humana, «conclusa y revisada» por Zubiri en los últimos meses de su vida (desde la primavera al verano de 1983) ${ }^{27}$, es donde se encuentra el tratamiento básico del fenómeno de la voz de la conciencia, que cabe prolongar y ultimar con las aportaciones publicadas en El problema filosófico de la historia de las religiones [PFHR] ${ }^{28}$ y El problema teologal del hombre: Cristianismo [PTHC] ${ }^{29}$.

\subsection{Análisis noológico de la voz de la conciencia}

En $H D$, la voz de la conciencia se presenta como un «fenómeno real» e «innegable», en el que se manifiesta el «problematismo de la fundamentalidad».

${ }^{26}$ G. Amengual, op. cit., pp. 425-428) remite a E. Levinas, De otro modo que ser (Sígueme, Salamanca, 1987) y a H. Jonas, El principio responsabilidad, Círculo de lectores, Barcelona, 1994).

27 Vid. Ignacio Ellacuría, «Presentación», HD, Alianza y Sociedad de Estudios y Publicaciones, Madrid, 1984.

28 Alianza y Fundación Xavier Zubiri, Madrid, 1993.

29 Alianza y Fundación Xavier Zubiri, Madrid, 1997. 
Zubiri comienza aclarando que la fundamentalidad de lo real no es una «causa», sino que acontece como «dominación»; este dominio es a lo que se ha de llamar «poder» (Macht): dominar es ser «más», es tener poder. No debería pasar desapercibido que es en el nivel trascendental de la realidad en el que se sitúa el poder: "El momento de realidad domina sobre la talidad, tiene poder. Por eso es "más" que la totalidad. Y este "más" es justo un aspecto de la respectividad constitutiva de la realidad en cuanto realidad» $(H D, 87)$.

Y Zubiri lo aplica en este contexto a la fundamentación de la realidad personal: «la realidad como fundante de mi realidad personal ejerce sobre mí un poder. La realidad es el poder de lo real» $(H D, 88)$. La dominancia no se identifica con la causalidad, pues no toda dominancia es causal. «Poder es la dominancia de lo real como real». «El poder se apodera de aquello sobre lo que domina. Dominancia es apoderamiento. El poder de lo real se apodera de mí. Y gracias a este apoderamiento es como me hago persona» $(H D, 88)^{30}$.

Por tanto, en este apoderamiento es donde «acontece la fundamentalidad», porque «lo fundante es el poder de lo real, el cual fundamenta apoderándose de mí». El apoderamiento por el poder de lo real no es una relación que una realidad ya constituida puede establecer o no, sino que es un momento constitutivo de la realidad personal. «Es una respectividad constitutiva». Por eso Zubiri afirma a continuación: «Soy realidad personal gracias a este apoderamiento, de suerte que este poder de lo real es una especie de apoyo a tergo no para poder actuar viviendo, sino para ser real» $(H D, 92)$.

Pues bien, este impulso que el hombre necesita para «estar haciéndose» a sí mismo es «versión al poder de lo real». «El apoderamiento nos implanta en la realidad» ${ }^{31}$, pero de un modo «paradójico», porque «al apoderarse de mí, me hace estar constitutivamente suelto "frente a" aquello que de mí se ha apoderado». Y es que, según Zubiri, «el apoderamiento acontece (...) ligándonos al poder de lo real para ser relativamente absolutos».

$\mathrm{Y}$ es éste el momento crucial en que aparece la noción de la religación. Pues a esta «peculiar ligadura» es a lo que ahora Zubiri denomina "religación»: «religados al poder de lo real es como estamos apoyados en él para ser relativamente absolutos» $(H D, 92)$. En definitiva, pues, «la fundamentalidad acontece en religación al poder de lo real» $(H D, 94)$.

30 Lo que se apodera de mí es lo que me fundamenta. Algo así como que «allí donde está tu tesoro, allí está tu corazón». A lo que estás vinculado es en lo que te fundas y en lo que te sostienes.

31 Recuérdese que la «implantación» era una de las expresiones que utiliza Zubiri para diferenciarse y distanciarse de Heidegger ya en la exposición de la analítica de la existencia en $N H D$, pero en la que todavía estaba ausente el «poder de lo real» - $\mathrm{y}$, por tanto, el «apoderamiento» - para explicitar cómo acontece la fundamentalidad. 
El subsiguiente análisis zubiriano del «hecho ${ }^{32}$ perfectamente constatable» de la religación al poder de lo real pone de relieve su carácter experiencial, manifestativo y enigmático, así como su diferencia de raíz con respecto a la «obligación», lo cual es de suma importancia para el esclarecimiento del significado de la «voz de la conciencia».

En primer lugar, Zubiri quiere dejar muy clara desde el principio la distinción entre religación y obligación: «La religación no es obligación, porque por el contrario, la obligación presupone la religación. Estamos obligados a algo porque previamente estamos religados al poder que nos hace ser. Para estar obligados tenemos que ser ya realidad personal, y sólo somos realidad personal por estar religados» $(H D, 93)$. Y concluye esta primordial diferenciación entre obligación y religación afirmando: «En la religación, más que la obligación de hacer, hay el doblegarse del reconocer a lo que hace que haya» $(H D, 94)$.

Un segundo aspecto que Zubiri quiere destacar es el «problematismo de la fundamentalidad» y es en ese contexto donde va a situar el peculiar fenómeno de «la voz de la conciencia» como uno de los momentos del problematismo de la fundamentalidad, debido sobre todo a que el poder de lo real tiene un «carácter enigmático». "Enigma es ante todo un modo de significar lo real», que consiste en indicarlo significativamente al modo de un «oráculo» $(H D, 96)$, es decir, con cierta «ambivalencia», que, según Zubiri, concierne no sólo al decir, sino a lo dicho, a «lo real». Lo real es enigmático, el poder de lo real es «un poder enigmático» $(H D, 97)$.

Dado, pues, que este enigma se nos manifiesta en la experiencia de la religación, nos tenemos que enfrentar al problematismo de la fundamentalidad: «Como el poder de lo real es enigmático, este enigma imprime su carácter a la realización de nuestra realidad personal: es el problematismo de la fundamentalidad. Nos hacemos problemáticamente porque estamos fundados en un enigma ${ }^{33}$, el enigma del poder de lo real» $(H D, 99)$.

Precisamente dedica Zubiri el apartado siguiente de su exposición a analizar este carácter problemático de la fundamentalidad, al que considera un «hecho innegable», distinguiendo tres momentos en tal problematismo: la «inquietud», la «voz de la conciencia» y la «volición sentiente».

En primer lugar, el problematismo se manifiesta en la «inquietud» y se expresa en las preguntas, tan características en la tradición de la filosofía española, por lo menos, desde Unamuno a Marías: «¿qué va a ser de mí?» y «¿qué voy a hacer de mí?». Es la inquietud radical de lo enigmático, que desde luego puede vivirse de diversas maneras: como deslizamiento, angustia, preocupación y ocupación en hacerse persona. Hay que destacar que Zubiri

32 ¿Tatsache o Faktizität? Si nos atenemos a la distinción heideggeriana, también en una Analítica noológica de la facticidad, tendría que entenderse como Faktizität.

33 Cursiva nuestra. Es muy significativo el crecido acercamiento de José Gómez Caffarena a este enfoque zubiriano en El Enigma y el Misterio (Trotta, Madrid, 2007). 
no quiere que se confunda la inquietud que es propia de la realidad humana en cuanto personal (estar ocupado en hacerse persona) con la «inquiescencia de la vida como decurso» (por la que en cada instante el hombre va deviniendo en el curso del tiempo y de los fenómenos que llenan este tiempo).

En segundo lugar, esta inquietud «tiene en cierto modo su contrapartida, por así decirlo, en otro fenómeno también innegable. En cada instante de su vida el hombre posee, en principio, eso que se llama voz de la conciencia» $(H D, 101)$. Es un «fenómeno real» y consiste en una voz que «dicta al hombre lo que ha de hacer o no hacer». Zubiri resalta que no se trata de una voz que hable sólo ni principalmente de «deberes», dado que «esta voz nos habla siempre en todo acto», en cada instante de la vida. de $H D$ ?

¿En qué consiste esta voz de la conciencia, según Zubiri en este contexto

1) La voz de la conciencia «sale del fondo de mí mismo». No es un fondo psicológico, sino «el carácter absoluto de mi realidad». «Mi radical fondo es el carácter absoluto de mi realidad». Este fondo es mío y no de otro. La voz de la conciencia emerge desde ahí, del fondo de mi propia realidad, de «lo absoluto relativo» que es «mío» y que «soy mí mismo» $(H D, 102)$.

2) La voz de la conciencia me dicta algo ${ }^{34}$. La voz de la conciencia puede ser clara u oscura, incluso «variable» a distintas personas y en distintas circunstancias y culturas, pero en todos los casos lo que la voz dicta es «una forma de realidad que he de adoptar».

La voz de la conciencia dicta de un modo «inapelable»e «irrefragable», es decir, que no se puede contrarrestar. Lo cual no quiere decir que el dictado sea unívoco, ni que haya de entenderse en el sentido de lo que Kant llamó «imperativo categórico», ya que Zubiri considera «falsa» esa interpretación kantiana por diversas razones: a) porque «esta voz no es un imperativo en sentido kantiano»; b) porque «Kant confundió siempre lo subjetual con lo subjetivo» («todo lo subjetivo puede ser subjetual, pero no todo lo subjetual es subjetivo») ${ }^{35}$; 3 ) porque «no se trata de un dictado categórico objetivamente considerado, sino de una voz en cuanto voz» $(H D, 102-103)^{36}$.

¿Qué quiere decir que la voz de la conciencia «es ante todo una voz»? Zubiri lo aclara indicando que esta voz es «una forma de intelección sentiente».

34 Con este punto se despejan algunas dudas surgidas a raíz de diversas cuestiones planteadas en la sesión del Seminario de Investigación Xavier Zubiri el día 3 de abril de 2009. Y cabe apreciar la semejanza y diferencia con respecto al análisis heideggeriano de lo que dice la conciencia al interpelado.

35 Esta apreciación de la filosofía kantiana podría corregirse mediante otras expresiones del propio Zubiri en que reconoce, por ejemplo, el sentido metafísico de la noción de persona moral en Kant (cfr. Xavier Zubiri, Sobre el problema de la filosofia y otros escritos (1932-1944), Alianza y Fundación X. Zubiri, Madrid, p. 252).

36 También en este punto habría que recordar algunas expresiones kantianas, expuestas más arriba, que estarían más allá de esta crítica de Zubiri y que cabría conectar con el nivel noológico. 
Cada sentido tiene su modo de aprehender lo real (la vista, el tacto, el oído, el sentido kinestésico, el de la orientación y el del equilibrio), de manera que hay muchos modos de aprehender lo real, es decir, de aprehender algo «de suyo», y uno de ellos es aprehenderlo en «hacia». Aquí la realidad es algo solamente «notificado».

Pues bien, Zubiri aplica a nuestro tema este esclarecimiento de los diversos modos de aprehender lo real a través de los sentidos: «La voz de la conciencia es justamente como una remisión notificante a la forma de realidad. Y aquello de lo que es noticia es la realidad. Desde este punto de vista, el hombre es la voz de la realidad. La voz de la conciencia no es sino el clamor de la realidad camino de lo absoluto» (HD, 104 y 137). Esta voz «clama» y nos lanza físicamente (no sólo intencionalmente) hacia el poder de lo real como enigma. «Es la voz del problematismo del enigma de lo real» $(H D, 104)$.

3) Como consecuencia, el hombre se encuentra «lanzado a tener que determinar la forma de realidad que ha de adoptar». Es el tercer momento del problematismo de la fundamentalidad. Esa determinación de la forma de realidad que ha de adoptar es lo que constituye la «volición sentiente». Un hecho constitutivo de la realidad personal. Y Zubiri se plantea la pregunta: «¿Cómo se presenta la realidad ante una volición?», a la que responde en tres pasos.

a) El modo de estar presente lo querido por la volición radical «es estar fundamentando nuestra realidad relativamente absoluta» $(H D, 105)$. Su modo de estar es «fundamentar», por tanto, no se tratará de «realidad-objeto», sino de «realidad-fundamento», dado que «su modo mismo de realidad, su modo de ser "de suyo", es fundamentar». Aun cuando no hay que olvidar en ningún caso que se trata, a su vez, de «la realidad como enigma» $(H D, 105)$.

b) Que estamos lanzados por la fundamentalidad a adoptar una forma de realidad significa tener que apropiarnos de una posibilidad. Y en esto consiste la volición: en «adopción o apropiación de una posibilidad de forma de realidad. Toda volición es volición de una posibilidad de forma de realidad» $(H D, 105$ y 106$)$.

c) Esta volición de forma de realidad no es una adopción arbitraria, ni es meramente «voluntad de vivir, sino voluntad de realidad personal». Por tanto, no se trata primariamente de «vivir», sino de «ser real»: es «voluntad de realidad» $\mathrm{y}$, en cuanto actualizada en la intelección, «voluntad de verdad» $(H D, 106)$. Esta voluntad de verdad podría signficar «voluntad de autentici$d a d »$ (según Zubiri, es lo que canonizó Nietzsche). «Pero esto es insuficiente porque hay un momento de voluntad de verdad que es anterior a la propia voluntad de autenticidad. Porque la autenticidad es la autenticidad en cuanto expresión de una realidad. Con lo cual descendemos a un estrato más hondo: a la voluntad de ser una realidad meramente actualizada en mi intelección. Es lo que he llamado verdad real» $(H D, 106)$.

Como es sabido, según Zubiri, la verdad real tiene tres momentos: 1) es ostensiva de realidad; 2 ) responde a lo que promete (es la verdad como fideli- 
dad, que para el hombre es seguridad); 3) es efectividad. Sus tres momentos, pues, son: manifestación, fidelidad y efectividad.

Por tanto, la realidad-fundamento es verdad real según estos tres momentos. Y esta verdad real es real en todos los modos de realidad, entre ellos según el «hacia». Estamos lanzados «hacia» en y por la verdad real. Y, por eso, «el hombre tiene que adoptar alguna forma de realidad entre otras posibles». «Y esto no es sólo una obligación, sino un hecho»: «el hecho constitutivo de la realidad personal del hombre» $(H D, 107)$.

Como la forma de realidad que el hombre ha de adoptar es optativa, «la voluntad de verdad real se plasma en búsqueda». Es «una experiencia de búsqueda de fundamento, de la fundamentalidad del poder de lo real», una experiencia a la que Bergson llamó «experiencia metafísica» y que Zubiri denomina «experiencia teologal» $(H D, 108)$. No obstante, veremos que, a pesar de ciertas dificultades (a las que se ha referido Diego Gracia), a partir del análisis zubiriano de la religación, tal experiencia podría denominarse asimismo, y quizá con más precisión, «experiencia religiosa».

Y todavía cabría añadir que a esta forma de entender la experiencia religiosa mediante el fenómeno de la religación va ligado el «hacerse persona», en tanto que experiencia de un poder enigmático, y de ahí que el hacerse persona sea «algo problemático», tal como se ha mostrado mediante los fenómenos de la inquietud, la voz de la conciencia y la volición de verdad real (enigmáticamente aprehendida). No es de extrañar, pues, que Zubiri acabe resaltando que «hacerse persona es búsqueda», a partir de la experiencia de un poder enigmático en la religación y del consiguiente problematismo de la fundamentalidad.

Tras exponer el tratamiento de la «voz de la conciencia» en $H D$, donde ya se ha puesto de manifiesto que la experiencia religiosa de la religación es el fundamento de la experiencia moral de la obligación, pasamos a considerar el lugar que ocupa tal fenómeno en las otras dos obras de la «trilogía teologal».

\subsection{El problema filosófico de la voz de la conciencia}

En El problema filosófico de la historia de las religiones se alude a «la voz de la conciencia» en diversos momentos, que corresponden a los distintos cursos de los que provienen los textos recogidos en esta publicación ${ }^{37}$.

El primer contexto en que nos encontramos con dicha noción es en la Primera parte de la obra, al estudiar el «hecho religioso», concretamente la «estructura de la religación», que es en la que - según la exposición de este texto - se actualiza la fundamentalidad del ser humano, en virtud de «la

37 Los cursos de 1965, «El problema filosófico de la historia de las religiones» (en Madrid) y «El problema de Dios en la historia de las religiones» (en Barcelona); el curso de 1968, «El hombre y el problema de Dios»; y el curso de 1971, «El problema teologal del hombre: Dios, religación, cristianismo». 
actualización de la poderosidad de lo real en tanto que deidad». También en este libro, pues, Zubiri deja claro que en la religación acontece la «fundamentalidad» y que, por tanto, no puede reducirse a un vínculo físico, ni a una presión social, ni tampoco siquiera a una obligación moral (PFHR, 40). Y la noción que emplea Zubiri para designar al fundamento real es «poder de deidad», al que caracteriza como un «poder, último, posibilitante, imponente» $(P F H R, 43)$. Lo primero que llama la atención es que aparecen aquí dos variantes terminológicas con respecto a la exposición de El hombre y Dios: ahora se utilizan los términos «poder de deidad» (a diferencia de «poder de la realidad») e «imponente» (a diferencia de «impelente»). No obstante, con independencia de la terminología, de lo que se trata es de expresar el «carácter universal y dominante que la realidad en cuanto tal tiene», en definitiva, «la realidad en su condición de poder» $(P F H R, 44)$.

Justamente en este momento es en el que se introduce el escenario en que aparecerá el lugar de «la voz de la conciencia» en la exposición de Zubiri. Pues, para afianzar la noción de «la realidad en su condición de poder», Zubiri afirma que no se trata de una «teoría», sino de un «hecho inconcuso». Y, por eso, «podrá un ateo no emplear la palabra deidad; me daría exactamente lo mismo» - dice Zubiri-, porque lo que Zubiri pretende es estar «describiendo» la «constatación» de un «hecho inconcuso»: que en el hombre acontece «el poder de la realidad», al que Zubiri se refiere aquí con el término «deidad» o «poder de deidad». Pero dejando claro inmediatamente que en la actualización de la poderosidad de lo real en la experiencia de la deidad sólo se trata de «la religiosidad, lo religioso en cuanto tal», pero no de una religión positiva ${ }^{38}$. Por tanto, Zubiri está aludiendo aquí a un sentido de «religiosidad» como «algo que constitutiva y formalmente pertenece a la estructura de la realidad personal», al «primordium esquemático de toda religión positiva». Pero, aún así, el propio Zubiri reconoce que sus afirmaciones pueden resultar chocantes. Pues «frente a la dimensión religiosa del hombre, aun tomada en toda esta amplitud, se esgrimirá la actitud del ateo» (PFHR, 53 y 54).

Ahora bien, según Zubiri, el ateísmo profesado es una posición de religación, incluso en la actitud del ateo que dice contentarse con «la facticidad del vivir». Porque la persona que tiene esa actitud «la abriga sinceramente en el fuero de su conciencia» y "oye la voz de su conciencia». Y «el que suene la voz de la conciencia, y tenga que atenerse a ella por lo menos para oírla, no es obligación, es religación: es la religación a su propia conciencia» (PFHR, 54). Por tanto, Zubiri entiende que el fenómeno de la voz de la conciencia no se reduce a una obligación moral y que sería un «error» — característico del idealismo de la autoconciencia- «pensar que el tener una conciencia moral es a su vez un acto de moralidad». A su juicio, «es el mismo error que cometieron todos los idealistas alemanes cuando creían que conocerse a sí mismo

\footnotetext{
38 En un apartado del texto, que corresponde al curso de Madrid de 1965 (PFHR, 53 ss.).
} 
es emitir un juicio segundo sobre un juicio primero, y así hasta el infinito» $(P F H R, 54)$. En cambio, Zubiri afirma que «la relación del hombre con su conciencia intelectiva no es lógica, sino que es física. Pues bien, la conexión de ese hombre con su conciencia no es una obligación moral; es una religación. La conexión primaria del hombre a su conciencia moral es una religación, y por eso esa actitud de aparente pura facticidad de la vida es (...) la religación a la conciencia» (PFHR, 54-55).

En suma, el análisis zubiriano cree poder descubrir que, incluso tras la mera «facticidad de la vida» del ateo, en un estrato más profundo, está la facticidad más básica y fundamental, en definitiva, lo que podríamos denominar la facticidad transcendental de la realidad humana, que es la religación. Y el análisis de la voz de la conciencia lo confirma, al poner de relieve que también en el fondo está expresando una relación — conexión- de religación.

El segundo contexto en que vuelve a aparecer la noción de la voz de la conciencia es en el «Apéndice. Divinidad y revelación» ${ }^{39}$. En él cabría resaltar los tres aspectos siguientes, que completan la exposición anterior.

(1) Se vuelve a destacar el nivel «último y radical» en que se sitúa el análisis zubiriano de la conciencia, que no consiste en «lo que» dice, sino en «el hecho de que esa conciencia me lo diga». Lo «esencial» es el «hecho», el «fenómeno» innegable del «dictar» de la conciencia, al que Zubiri denomina «la voz de la conciencia». Precisamente en esa voz de la conciencia es en la que está la «fuerza incoercible» del dictar de la conciencia y en la que queda «actualizado religadamente el poder de la deidad» $(P F H R, 64)$.

(2) Se introduce una nueva terminología referida a la actividad del «espíritu humano» para caracterizar la actuación de la voz de la conciencia, pues ésta — que «brota de la realidad misma como fundamento de la deidad»— «consiste en la resonancia del fundamento de la deidad que está agitándose en el seno del espíritu humano» $(P F H R, 65)$. En la voz de la conciencia no tenemos el fundamento, sino sólo tenemos la «resonancia» que «remite» al fundamento en virtud del cual la realidad resuena en forma de deidad. Dicho con la nueva terminología utilizada en estos contextos: «La voz de la conciencia no es sino la palpitación sonora del fundamento - es decir, de la divinidad misma- en el seno de nuestra conciencia, en forma pura y simple de ese dictar cuyo contenido se nos escapa de momento» $($ PFHR, 66). Es decir: en la voz de la conciencia tenemos «la palpitación y el latido de la divinidad en el seno del espíritu humano» (PFHR, 66 y 67). Es muy probable que esta terminología se deba a la incorporación de elementos provenientes de la teología mística, que permiten comprender mejor una forma de intelección sentiente, aprovechando el lenguaje de los sentidos para expresar esa «palpitación»o «latido de la divinidad en el fondo del espíritu humano».

39 El texto proviene del curso de Barcelona en 1965 (PFHR, 61-77). 
(3) Se insiste en que la voz de la conciencia no es un fenómeno meramente moral, sino que tiene un carácter «estrictamente metafísico», que se actualiza en forma de resonancia — intelección! - auditiva en el yo religado $(P F H R, 67)$. De ahí que «por la voz de la conciencia» se abra un camino «estrictamente metafísico» para ir a Dios. Pues no se trata de una vía meramente subjetiva, sino real — metafísica - a través del hombre como realidad. «Desde este punto de vista, Dios es un fundamento real en la realidad, un fundamento del poder de la deidad de lo real, que palpita en el fondo del espíritu humano...» $(P F H R, 68)^{40}$.

El tercer contexto es el de «La accesibilidad de Dios» ${ }^{41}$ y en él aparece un nuevo aspecto de lo que significa la voz de la conciencia en Zubiri, que no había emergido hasta ahora, a saber, el de la «revelación». En efecto, al hilo de su exposición de la «accesibilidad de la realidad divina» presenta tres conceptos: la fontanalidad divina, la presencia interpersonal y la manifestación de la realidad de Dios. La voz de la conciencia queda conectada con este tercer concepto. Pues esta manifestación consiste en «la presencia real y efectiva de Dios como realidad personal en el fondo de toda persona humana», que es lo que funda «la voz de la conciencia como poder de lo real». «La revelación está esencialmente anclada y dirigida a la voz de la conciencia» (PFHR, 72). Es en el concepto de la voz de la conciencia donde quedan reasumidos el carácter de presencia fontanal y de presencia interpersonal, que convergen en el carácter de «presencia manifestante» de la realidad divina «en el fondo del espíritu humano». Con lo cual se está afirmando que «Dios está manifiesto en el fondo de todo hombre, sépalo o no lo sepa, aunque sea en esa forma tan vaga, pero tan clara y perceptible, que es la voz absoluta de la conciencia» $(P F H R, 73)$. Por eso, se puede decir también que «Dios está siempre revelado» ${ }^{42}$.

El cuarto contexto es el «Apéndice. La verdad religiosa» ${ }^{43}$. Aquí aparece de nuevo la voz de la conciencia en relación con «el que no tiene religión ninguna», de un modo semejante a otro contexto anterior - el primero-, puesto que, según Zubiri, incluso esa persona no carece de «esa forma de religación o de religión personal que es la voz de su conciencia» $(P F H R, 159)$. En la voz de la conciencia está presente la divinidad y Zubiri lo ejemplifica remitiendo, no sólo a san Pablo (los paganos tienen inscrita en sus corazones la Ley de Dios) ${ }^{44}$, sino al caso de un «brahmán» o de un «panteísta cualquiera», pues también su conciencia «refleja el orden cósmico».

40 Cfr. también PFHR (pp. 64 y 304) y PTHC (p. 69, donde se remite a la «inmanencia metafísica de la divinidad en el seno del espíritu humano»).

41 Texto del curso de 1968 (vid. nota en pp. 68-69 y en p. 39 de PFHR).

42 «Dios está revelado siempre, a todo hombre y en todo momento de la historia y en todas las formas históricas» (PFHR, 72). Véase también X. Zubiri, PTHC, pp. 69-70.

43 Procede del curso de 1965 en Madrid. Cfr. PFHR, pp. 151-164.

44 Cfr. Rom 2, 15. 
El quinto y último contexto en que aparece en esta obra nuestro tema es el de «El cristianismo y la razón moderna» ${ }^{45}$. De nuevo emerge aquí un aspecto fundamental en el pensamiento de Zubiri: el de la vías para llegar a divinidad como fundamento de la deidad, que plantean el problema de los «tipos posibles de fundamento». Aunque la razón no llegue a la divinidad, según Zubiri, «siempre queda el hecho inconcuso de que el hombre configura su ser personal en su versión a la realidad en cuanto tal, en tanto que última, posibilitante, imponente; esto es, todo hombre, llegue o no a la divinidad, está religado a la deidad y, recíprocamente, actualiza la deidad en su religación como fundamentalidad de su ser personal» (PFHR, 300-301). Así pues, aunque el ateo y el agnóstico no encuentran el fundamento de la deidad, según Zubiri, a lo que «apelan como ultimidad posibilitante y además imponente» es al «dictado de su conciencia en cada caso. Este dictado es lo que constituye la voz de la conciencia». En esa actitud positiva que apela a la conciencia se actualiza el poder de la deidad (sin Dios o sin dioses). Dado que esta actitud positiva que Zubiri cree descubrir «es un momento esencial de la elaboración consciente del ser de la persona humana», habrá que analizarla más detenidamente, puesto que, según Zubiri, viene a ser «el problema filosófico de la voz de la conciencia» (PFHR, 301).

La voz de la conciencia tiene dos dimensiones: 1) lo que la conciencia dicta: la obligación (aunque Zubiri aclara que no quiere decir que todo lo que la conciencia dicta sea obligatorio, sino que también alumbra posibilidades de realizar lo que se va a ser y a hacer); y 2) el dictar mismo en cuanto tal, que no tiene carácter obligatorio, pues que tenga que atenerme al dictado de mi conciencia «no es una obligación, sino una forzosidad». Aunque se la puede contrariar, en esa contrariedad se muestra un aspecto positivo, que es «lo esencial de la voz de la conciencia»: «el dictar mismo». Es decir, «si bien lo que dicta la conciencia es un deber, algo intencional, la fuerza del dictar mismo no es intencional sino física» $(P F H R, 302)$.

A partir de esta distinción entre las dos dimensiones de la voz de la conciencia Zubiri intenta dilucidar en este contexto lo que considera el problema filosófico que hay en el fondo de tal noción, a saber: el de la peculiar «relación» del hombre con su conciencia, que, a su juicio, no es de «obligación», porque esto supondría caer en un error semejante al del idealismo de la autoconciencia. Pues tampoco la relación de la conciencia consigo misma es auto-conocimiento. Hay un auto-conocimiento, porque hay un autós capaz de reobrar sobre sí mismo. La reflexividad de la conciencia es una reflexividad pre-cognoscitiva, es un momento físico de la inteligencia. Así pues, «tener que seguir la voz de la conciencia» es algo previo al dictado de la conciencia,

45 PFHR, cap. VI, titulado «El cristianismo como religión intrínsecamente histórica». Curiosamente se trata de unas páginas manuscritas, añadidas al texto mecanografiado (cfr. $P F H R$, nota, p. 300). 
es un momento físico de la conciencia. Por tanto, la «relación» del hombre con su conciencia no es una obligación, sino una «voz», algo «físico», una «fuerza». Por eso, «el problema filosófico de la voz de la conciencia se centra en la dimensión física de una voz que dicta» (PFHR, 302).

¿En qué consiste esa voz? Zubiri responde como sigue. Primero, es una voz que me dicta a mí: es «voz a». Es un momento físico que me tiene forzado. Es el momento físico que llamamos «poder», aquello a que también apelan el agnóstico y el ateo). «Este dictarme es lo que constituye el poder último, posibilitante, imponente». Es lo que nos tiene religados, pues la religación tiene esta dimensión de «voz-a» mí de la conciencia. Y por eso, según Zubiri, también el agnóstico y el ateo están religados a un poder último, posibilitante, imponente, que es la voz que dicta en su conciencia. Pero, en segundo lugar, la voz de la conciencia tiene otro aspecto: el de «voz-de». Pues es una voz que dicta desde la conciencia misma y Zubiri advierte que «es a lo que certeramente apunta la expresión: voz de la conciencia» ${ }^{46}$. Y recuerda, a continuación, que la voz es una estricta intelección auditiva, que el poder con que la voz de la conciencia me hace atenerme a la realidad está presente en la voz de la conciencia y que en este atenimiento está actualizado el poder de lo real. Y, para concluir, Zubiri resalta de nuevo el aspecto, a mi juicio, más radical de su análisis: la no reducción de la voz de la conciencia a un fenómeno moral. La voz de la conciencia no es un fenómeno meramente moral, sino que es «la voz de la realidad que remite a su fundamento, y que palpita sonoramente en el fondo de esa realidad que soy yo, de mi realidad absoluta» (PFHR, 304). «Religados a la realidad última, posibilitante, impelente, su poder nos hace ser absolutos, nos inquieta radicalmente, y nos llama en la voz de la conciencia, por la que todo acto, por modesto que sea, está remitido al fundamento real de ese poder» (PFHR, 305).

En suma, el análisis zubiriano de la voz de la conciencia nos ha situado no sólo ante un fenómeno moral, sino que nos ha conducido a un estrato más profundo de carácter metafísico y noológico, el de la facticidad transcendental y noérgica de la realidad.

\subsection{Conexión noológica de religiosidad y moralidad}

Tras lo expuesto, podemos concluir que la voz de la conciencia constituye un lugar de encuentro entre la experiencia religiosa y la experiencia moral. La voz de la conciencia es tanto un ingrediente de la religión personal como la manifestación de la conciencia moral. La experiencia religiosa (de la religación) es el fundamento de la experiencia moral (de la obligación). La voz de la conciencia (re)suena en la facticidad de la vida. En el estrato más profundo

46 Zubiri remite al curso de 1968, en el que ha abordado el problema de la voz de la conciencia (cfr. PFHR, nota de p. 303). 
de la realidad personal hay una religación a la propia conciencia, una conexión de religación. La religación es la facticidad transcendental, que tiene un carácter noérgico.

Esta vinculación del sentido religioso y moral de la vida humana, que arraiga en los estratos noérgicos de la existencia, tiene que ver fundamentalmente con el reconocimiento (tal cual se expresa en el análisis zubiriano de la religación) y puede servir de fundamento noológico (noérgico) incluso de la resistencia y la fuerza potencialmente disidente de la conciencia moral de cada individuo, como ha resaltado Javier Muguerza, convirtiéndola en la instancia fundamental de su «individualismo ético» ${ }^{47}$.

Lo crucial en la concepción zubiriana de «la voz de la conciencia» consiste en que se pone de manifiesto la dimensión religiosa de la realidad personal, que queda así revelada por la voz de la conciencia. Así pues, en este componente de la facticidad de la experiencia quedan conectadas la moralidad y la religiosidad, la experiencia moral y la religiosa. Y no creo que sea un inconveniente irresoluble contar con la noción de «experiencia», ni haya que abandonar dicho término en este contexto zubiriano, como propone Diego Gracia ${ }^{48}$, pues cabría distinguir en Zubiri entre «experiencia campal» y «experiencia mundanal», como ya propuse tentativamente, a fin de armonizar la propia terminología de Zubiri en diversos momentos de su producción ${ }^{49}$.

En conclusión, lo primordial en la facticidad noológica no es la voz de la conciencia moral, sino que en ella resuena algo más: la experiencia religiosa en su sentido más originario. Desde la perspectiva de la filosofía zubiriana de la religación, el último fondo es el carácter noérgico de la facticidad de la realidad, que se actualiza en la intelección sentiente, tanto en el poder de lo real como en la voz de la conciencia. Por tanto, la experiencia religiosa que lleva consigo el fenómeno - el hecho, el factum - de la religación (en el peculiar sentido zubiriano) cuenta con estos dos ingredientes que ha descubierto el análisis noológico: el «poder de lo real» y la «voz de la conciencia».

47 Vid. Javier Muguerza, Desde la perplejidad, F.C.E., México-Madrid, 1990, pp. 330 ss. y 376; y Carlos Gómez, «Conciencia moral», en A. Cortina (dir.), 10 palabras clave en Ética, Verbo Divino, Estella, 1994, pp. 17-69.

48 Vid. Diego Gracia, «El problema del fundamento», en J. Nicolás y R. Espinoza, Zubiri ante Heidegger, Herder, 2008, pp. 33-79.

49 Vid. Jesús Conill, «Concepciones de la experiencia», Diálogo Filosófico 41 (1998), pp. 148-170. 